\title{
Constructing vocational knowledge: History, communities and ontogeny
}

\author{
STEPHEN BILLETT \\ Griffith University, Australia
}

\begin{abstract}
This article examines how different forms of vocational knowledge are constructed from social sources. Using a Vygotskian framework it is claimed that in different ways vocational knowledge is shaped by history, community and ontogeny through microgenetic development. This process of ongoing problem-solving links social circumstances to the development of the cognitive structures necessary to conduct vocational practice. It is held that such findings help explain the limitations of transfer and also the need to conceptualise expertise at the particular community of practice, rather than at some disembedded level of practice.
\end{abstract}

\section{Introduction}

Significant questions remain to be answered about the origins and source of vocational knowledge and how individuals access and construct that knowledge. The Vygotskian constructivist perspective holds that knowledge has socio-historical origins and is appropriated by individuals through interpersonal (proximal) guidance, or through more indirect (distal) forms of social guidance within social practice (Rogoff, 1990; 1995; Scribner, 1984, 1992; Scribner \& Beach, 1993; Vygotsky, 1978, 1987). It is held that, an inter-psychological process, between individuals and social sources, precedes the appropriation of intra-psychological attributes which grant facility to thinking and acting. However, appropriation is not the mere internalisation of externally derived knowledge. Rather it is an active process of individuals interpretatively constructing knowledge based on their existing knowledge structures (Rogoff, 1995). This process is likened to individuals' search for viability (von Glasersfeld, 1987) as they seek to integrate what they experience with their existing knowledge structures. Furthermore, it is held that, initially, individuals' construction of knowledge is idiosyncratic. Newman, Griffin \& Cole (1989) contend that if individuals' construction of knowledge were the same there would be little need to communicate. Instead, it is through ongoing social mediation within the social circumstances associated with knowledge's deployment that the structuring of knowledge is likely to become more coherent, congruent and communicable. These claims pose important questions for the way that social mediation organises the structuring and development of vocational knowledge.

This article examines how individuals construct vocational knowledge by engaging in practice in particular social settings, and how the influence of those circumstances is mediated by 
individuals' prior knowledge premised on their personal histories. In order to achieve these goals the paper, firstly, overviews forms of knowledge which are deployed in vocational practice, and as such constitute the types of knowledge which might be the goals of vocational education. This is followed by an account of sources of knowledge synthesised from the socio-cultural literature. Next, a study which examined how vocational knowledge is constructed by individuals participating in four different settings is briefly described and findings overviewed. It is concluded that contributions from history, community and ontogeny need to be acknowledged when seeking to understand how and in what forms vocational knowledge is constructed. Finally, implications for vocational education are advanced.

\section{Forms of knowledge}

In this section forms of knowledge which are commonly referred to within cognitive psychology are delineated and, in addition, 'non'-cognitive dispositions are advanced as being central to the deployment of these cognitive structures. Cognitive structures are usually viewed as being the representation of knowledge in memory which interact to secure goals during cognitive activities, such as problem-solving or transfer (Stevenson, McKavanagh \& Evans, 1994). These structures, developed over time, provide a foundation for expert performance. Learning, transfer, and problem-solving, are associated with testing and modifying cognitive structures (Glaser, 1984; 1989; 1990). The usual distinction within cognitive structures is that between conceptual (propositional) and procedural forms of knowledge (Anderson, 1982; Glaser, 1984). However, it is proposed that deliberations about cognitive structures need also to account for dispositions, which comprise interest, values and attitudes (Garner, 1990; Prawat, 1989), and which are usually viewed as being 'non'-cognitive attributes. It is advanced below that the cognitive structures and their deployment are inherently dispositional (Perkins, Jay \& Tishman, 1993). These forms of knowledge are now described in more detail.

Propositional knowledge or knowledge 'that' (Ryle, 1949), also termed declarative knowledge (Anderson, 1982) comprises facts, information, assertions, concepts and propositions. A base of conceptual knowledge provides a foundation for adaptable thinking and acting (Gott, 1989). Complexity of propositional knowledge is referred to in terms of depth. Deep conceptual understanding is the acknowledgment of the possession of complex conceptual understanding 
(Greeno, 1989) and includes the strength of associations among concepts (Groen \& Patel, 1988; Novak, 1990). Procedural knowledge (Anderson, 1982) is the form of knowledge enabling skilful action (Best, 1992). Also termed 'knowledge how' (Ryle, 1949), procedural knowledge comprises techniques, skills, and the ability to secure goals (Stevenson, 1994). Procedural knowledge has also been further classified into levels or orders (Evans, 1991; Scandura, 1980; 1982; Stevenson, 1986a; 1991). Stevenson (1991) proposes three levels of orders. First order or specific procedures are employed to achieve specific goals. When non-routine or ill-defined tasks are encountered specific procedures are not effective being specific to routine situations. Consequently, a conscious monitoring, evaluation and strategy selection procedure, the second order, is invoked. The second order includes procedures, such as those needed for breaking the task up into a series of sub-goals (Greeno \& Simon, 1988). The first and second order are managed by forms of third or higher-order procedural knowledge which act executively upon the lower orders of procedures (Evans, 1991; Scandura, 1982; Stevenson, 1986a; 1991).

Having considered deepening layers of propositional knowledge and levels of procedural knowledge, a gap becomes apparent in the literature - the dispositions which underpin these representations. In reviewing Ryle's (1949) categories of knowledge 'that' and knowledge 'how', Martin (1971) noted that some behaviour did not fit into either of these categories. How can being pleasant to customers in a retail or restaurant setting, or the appropriate level of checking and self-monitoring required of a motor mechanic be categorised? Therefore, it is necessary to examine dispositions which underpin the cognitive structures and their deployment in skilful activity.

Dispositions comprise attitudes, values, affect, interest and identity (Prawat, 1989). Perkins, Jay and Tishman (1993) conceptualises dispositions, as individuals' tendencies to put their capabilities into action. Although the role of strategic procedural knowledge - knowing how and when to apply knowledge - has been acknowledged (see Evans, 1991, Gott, 1989), this does not adequately account for dispositions. Strategic knowledge is concerned more with the efficacy of securing goals, than whether the learner thinks they are worth securing, as Goodnow (1990) and, Dweck and Elliot (1983) argue, or whether individuals possess the personal confidence or motivation to proceed with the task (Belenky et al., 1986). The distinction between dispositional 
and strategic knowledge becomes apparent when the issue of values is considered. Dispositions determine whether an individual values a particular form of knowledge enough to be willing to participate in the effortful activity required to secure and then utilise that knowledge. For example, Dweck and Elliot (1983) suggest that school students, with a performance orientation, may determine if participation in a particular activity will result in them "looking smart", which is quite a different disposition from those who seek to determine what they will learn from an activity before participating. The motivation to engage in cognitive activity is different from the view of strategic knowledge which focuses on the efficacy of activity, which de-emphasises the personal and social values which influence activity.

However, rather than advancing dispositions as a separate category of knowledge, they are viewed as underpinning both propositions and procedures (Perkins, Jay \& Tishman, 1993). These forms of knowledge are therefore viewed as being inherently dispositional. To ignore the role of dispositions is to render these categories of knowledge as being inert, non-problematic or value-free, which thinking and acting are not. Consequently, cognitive structures are held to be

underpinned by dispositions. Having discussed these forms of knowledge it is necessary to consider their sources. The socio-cultural literature suggests knowledge is socially sourced and constructed as a social process.

\section{Sources of knowledge}

Learning, within the Vygotskian view, is conceptualised as being a social and cultural activity, which links the evolving history of the species to individuals' histories, through the learning of historically-derived culturally-generated knowledge. Vygotsky (1987) proposes that complex thinking is derived socio-historically, rather than through individual biological development (Gauvain 1993; Luria, 1976). However, whereas Vygotsky saw a direct interaction between the individual and the evolving social world, others (Rogoff, 1990; Scribner, 1985b) have offered hierarchies of practice, which are socio-cultural in origin and suggest that cultures and communities do not progress at the same rate or even in the same direction. Using examples of counting systems, which utilises artefacts and symbol systems which are culturally generated, it is possible to demonstrate that the attributes of individuals were transformed by sociallydetermined thinking processes in learning to count (Scribner, 1985b). Therefore, it is held that, 
as the world is socially-constructed, patterns of behaviour have their origins in social action and activities. It has been advanced that within any given socio-cultural setting significant experiences occur in patterned ways (Scribner, 1985a) and this patterning is a product of socially-determined activities. Activity theory, as advanced by Leonteyev (1981), views cognitive and motivational processes as being embedded within "larger activity structures whose goals they serve" (Martin \& Scribner, 1991:582). Activity is seen as being transformational, as it provides mediation between the individual and the social context, and involves reciprocal interaction and transformations (Leonteyev, 1981; Scribner \& Beach, 1993). Activity is therefore held as being an explanatory principle for practice which in turn influences learning.

Particular communities of practice, such as a workplace settings, appear to provide a coherent unit for analysing the sourcing and appropriation of vocational knowledge. A community of practice is defined as a set of relations among persons, activity and world, over time and in relation to other tangential and overlapping communities of practice (Lave \& Wenger, 1991:98). Signalling the centrality of practice to knowing, these writers state that "a community of practice is an intrinsic condition for the existence of knowledge, not least because it provides the interpretative support necessary for making sense of its heritage" (1991:98). So workplaces seem to fit the requirements of what is advanced by Lave and Wenger (1991) advance. The community of practice is shaped by an activity system (Engestrom, 1993) whose relational elements comprise the social system which underpins practice. The culture of practice comprises the norms and practices of the community (Brown, Collins \& Duguid, 1989). It is the culture of practice which determines what knowledge is privileged in a particular setting. Therefore, it is held that participation in a particular community of practice offers access to historically-derived knowledge which is privileged in certain ways by the community of practice.

Individuals participate in overlapping communities of practice and appropriate knowledge over time, which is referred to as ontogenetic development, or changes in thinking arising from the history of individuals (Rogoff, 1990:32). Participation in particular practice is viewed here as a form of continuous learning through problem-solving referred to as microgenetic development (1990:32). Microgenetic development is viewed as the moment by moment learning that occurs through participation in goal-directed activity of problem-solving. This problem-solving is both 
routine and non-routine which together are generative of new cognitive structures and their reinforcement through everyday practice. To conceptualise these sources of knowledge from theory, the historical, community and individual sources of knowledge have been identified in Table 1.

Table One about here

In order to appraise these theoretical concepts, a study was undertaken to determine how participating in communities of practice shape vocational practitioners' representations of knowledge and approaches to solve problems. A brief description of the study and its findings now follow.

\section{Method}

The investigation comprised a study of the same vocational practice occurring in four different settings. This study comprised of an ethnographic style of investigation into the activity systems within the salons and also the personal histories of the subjects. In addition, the subjects responded to a set of identical hairdressing problems. Hairdressing was selected as vocational activity and settings (hairdressing salons) were located in three different locations in Queensland, Australia and one in the United Kingdom. Eleven subjects (hairdressers) participated in this investigation, and of these, four were apprentices in the final stages of their indenture. In order to secure a rich understanding of individuals' structuring of knowledge a series of ill-defined problems were used. These type of problems are more complex than well-defined problems, as in the former, the start state is vague and goal state unclear, and operations required to change start state to goal state are also unclear (Chi, Glaser \& Farr, 1988). Thus an effect of ill-defined problems is the need to elaborate more information about start state (Voss, Blais, Means, Green \& Ahwesh, 1986). These types of problems are viewed as being particularly valid for inquiry into the acquisition of vocational knowledge because problem situations in vocational activities are often ill-structured, with the solver having to construct the goals (Gott, 1989). Knowing which representations are selected from an array of all the possible representations provide a great deal of knowledge about the psychology of solver (Newell and Simon, 1972). Greeno and Simon (1988) propose that problem-solving task involves three forms of knowledge: problem- 
solving operators (procedures); perceptual concepts for pattern recognition (concepts), and strategic knowledge (higher order procedural knowledge). They argue that in the task of problem-solving these forms of knowledge perform interdependent functions. Operators (procedures) respond to concepts (theories, postulates and definitions) which are used to justify steps in solution search. Strategic knowledge sets goals that organise problem-solving activity operating in an executive capacity (Evans, 1991).

\section{Findings}

The findings of the study revealed both similarities and differences in the subjects' responses to problem-solving activity. Patterns of consistency was discernible in the responses across all four settings for some specific procedures and those with a more general application, as well as concepts of both a general and more specific form. For example, subjects, regardless of setting, referred to using similar goals and procedures to guide their overall activities. The initial formulation of goals, which can be viewed as the start state of the problem, were quite similar. So, for example, when confronted by a photograph of a particular client all eleven subjects, regardless of their location, conceptualised aspects of the problem in a similar way. The hairdressers used face shape, condition of the hair or balance of the existing haircut to generate goals for the treatment. Yet, beyond this the subjects generated quite different goal states, and utilised variations of procedures to secure these goal states. The formulation of goal states and preference for a particular set of specific procedures (techniques) were linked to the subjects' participation in a particular community of practice. For example, there were types of treatments which were privileged at each salon (cut and colour; chemical and colour; neat and tidy). That is, there was similarity in the goals and procedures for subjects within each of the settings. Moreover, the details of the goal state, and hence choice of procedures appeared to be closely linked to the subjects' preference, which were based on their personal histories and ontogenies. Given choice subjects recommended those treatments which they had reported as preferring or enjoying. The source of these preferences was usually able to be sourced in positive experiences in their ontogenies.

Therefore, it was inferred from the data that some representations were common across all four settings, some were consistent within a setting and some linked to individual's ontogenies. From 
the analysis of the protocols it is interpreted that three sources of knowledge are evident which shape individuals' representation of knowledge.

1. There is canonical knowledge which is historically derived and consistent across the four settings. Represented in forms of concepts and procedures they vary from broadly applicable (e.g determine, negotiate and monitor treatment) to very specific procedures (e.g shorten long hair for a change), and, from broad conceptualisations of hairdressing tasks (e.g goals of client satisfaction or concerns about client's management of hair) to quite specific concepts particular facets of hairdressing (e.g balance of cut, size of face).

2. Knowledge privileged within a particular community of practice can be thought of as being an embedded version of the canonical practice of hairdressing. These representations are accessible in forms of concepts and procedures, appear to favour certain conceptualisation of problems and procedures for securing goals (e.g. salon's strategic goals - 'change-maker' or 'maintaining clientele' or 'managing demanding clients') emphasis on particular procedures (e.g - threaded 'piecey' styles at one salon) in the form of norms and practices - the culture of practice.

3. The construction of vocational knowledge is mediated by individuals' personal histories or ontogenies. This source offers both preferences and dispositions and is accessible in forms of concepts and procedures. Particularly evident were preference for procedures (techniques) and dispositionally embedded concepts (e.g some subjects didn't like colours or chemicals and avoided offering these treatments).

The general goals and rules associated with hairdressing (canonical knowledge) appear to provide a start state for problem-solving. However, the development of the problem-space - the array of possibilities - is constrained by the particular socially-determined circumstances - the culture of practice. It is the particular privileging in the community of practice which appears to present the hairdressers with parameters for the problem-space. The community of practice privileges a range concepts and procedures as a basis for the problem space, which the subjects interpretatively construct. The idea of privilege at the community level should not be seen as 
simply a preference for one approach over another. Instead, it refers to how tasks are undertaken and the steps associated and procedures utilised. Furthermore, using their conceptualisation based on personal dispositions, subjects select an appropriate solution strategy. This strategy selection was reported as being influenced by the subject's personal history. However, there are two qualifications here. Firstly, given the negotiated nature of hairdressing the individual hairdresser will not be always able to select a preferred strategy. That is, the hairdresser can recommend a particular approach, yet the degree to which the client will accept this recommendation is a negotiated one. Secondly, the individuals standing in the community of practice influences the degree by which they were able to exercise their personal preference. That is those who own or manage a salon are more likely to believe that they can exercise their preference than a more peripheral participant, for example, an apprentice.

The significance of these findings is are two-fold. First, historically derived socio-cultural knowledge is accessible in particular communities of practice. The utilisation of this knowledge in a particular community of practice can be seen as the application of a version of historically derived socio-cultural practice, which is privileged and shaped by the community's activity system. Second, the linkages afforded by the particular community of practice between the socio-historic development and individuals' personal history provide a basis to understand the constructive process of learning as being socially-determined in both immediate circumstances and throughout individuals' personal histories.

\section{Discussion: Microgenetic development mediating history, community and ontogeny}

Subjects in the salons, regardless of setting, referred to using similar goals and procedures to guide their overall activities. At the more specific level of the community, they applied similar approaches to handle client complaints and offered a particular pattern of treatments. The initial formulation of goals, which can be viewed as the start state of the problem, are quite similar. Yet, beyond this commonality the subjects generated quite different goal states, and utilised variations of procedures to secure these goal states. The formulation of goal states and preference for a particular set of specific procedures (techniques) appeared linked to the subjects' participation in a particular community of practice. However, within particular communities of practice, the concepts and procedures exhibited a common characteristic which related to a 
privileging of activities within the community. As stated earlier, the community of practice determines what is worth doing well, and what is not. Moreover, the details of the goal state, and hence choice of procedures appeared to be closely linked to the subjects' personal preference. Therefore there was evidence that history, in the form of canonical knowledge, was evident as was community and ontogeny. In this way, the influence of these forms of social practice have been identified.

In order to account for and interpret these findings in a way that informs about vocational knowledge and its development, it is useful to consider the phases of problem-solving in relation to the development of the problem-space constructed by the problem-solver (hairdresser). The problem space is a construct organised by the problem solver when set parameters for how the problem might be solved (Greeno \& Simon, 1988; Newell \& Simon, 1972). With ill-defined problems it is necessary for the solver to also construct and goal state. In this way the problem space represents the responses to the start state and solutions are generated by how and in what way the solver construes the goal state. The general goals and rules associated with hairdressing that are commonly stated appeared to provide the start state for problem-solving, these are those canonical elements which are historically-sourced. However, the development of the problemspace - the array of possibilities - is constrained by the particular socially-determined practice. The everyday practice, shaped through the activity system, makes demands which influenced the basis of the actual problem space the individual works within. So canonical concepts and procedures (both general and procedural) are accessible and realised in a particular practice. It is the particular privileging in the community of practice which presents the practitioner with parameters for the problem-space. Using their own conceptualisation based on their personal dispositions, they then select an appropriate solution strategy. This selection strategy is also influenced by their personal histories. All of this would only provide evidence that knowledge is influenced by a number of social sources, if it were not for the link between cognitive development and problem-solving, as outlined above. Hence it is inferred from the data that problem-solving activity which has cognitive consequences is shaped by different social sources.

\section{Conclusions}

The findings from this study have indicated ways in which social practice influences mental 
functions. In doing so it contributes to the unfolding deliberations about the relationship between social sources and individuals' thinking and acting. No longer is it possible to consider cognitive activities without consideration of the social and cultural context in which cognitive activity occurs. The circumstances in which the subjects engaged in vocational practice are shaped microgenetically by social influences which comprise history, community and ontogeny. As the deployment of knowledge in routine and non-routine problem-solving is equated to learning and, therefore, cognitive development, it is held that the construction of vocational knowledge is shaped by circumstances of the problem-solving activity. Subjects constructed and utilised knowledge that is socio-culturally canonical; having a more universal application. In this way, the particular circumstances are seen to produce representations of knowledge in memory that are general in application and also quite specific to particular circumstances. What is being suggested is that contrary to criticism of learning situated in one setting developing fragile forms of knowledge, instead general and adaptive representations of both conceptual and procedural knowledge are accessed in these particular settings. The richness of this access is one determined by privilege, whether robust or brittle knowledge is appropriated is in part a product of what is privileged in that community. However, what the data infers is that key elements for performance are highly situated. Hence, there can be no guarantee that transfer from one setting to another will occur. This is likely to be particularly the case if there was greater differences between settings (e.g. between a workplace and a vocational college).

From the findings it is evident that three sources of representations of knowledge are involved in the problem-solving activity (history, community and ontogeny). These sources not only emphasise the social origins of knowledge they provide evidence of the different contributions of different sources in complex thinking activities. The significance of these findings is firstly, that domains of knowledge and concepts of expert (competent) performance are situated within the circumstances of where knowledge is constructed, deployed and expertise judged.

Secondly, the goals and means of securing the goals for vocational practice are likely to be shaped by the particular community of practice in which knowledge is acquired and deployed. This may go some way to explain the difficulties associated with transfer of knowledge from one situation to another, particular when the circumstances are remote (e.g. from the training 
room/vocational college to the workplace). The communities of practice in these settings are quite different, with resulting consequences for the construction and deployment of knowledge. Thirdly, this problem requires that modes of guided learning be considered to assist the closing of the differences between the circumstances where knowledge is acquired and then used.

In summary, the social sourcing of knowledge appears to be, at least, threefold. There is the evolving socio-historical source of vocational knowledge. This source evolves overtime and enjoys mutuality with the situations where this knowledge is applied and transformed. Second, there is the particular circumstance of this vocational knowledge's application. The way in which that knowledge is privileged is determined by the activity system which defines the culture of practice, that is the norms by which practice is conducted. Individuals participating in the particular social circumstances are given access to the socio-historical forms of knowledge, through the activity system which shapes its use in a particular context. However, the third source of knowledge is the individual's ontogeny which provides an interpretative framework by which knowledge is structured and appropriated. To conclude it is held that the construction of vocational knowledge and individuals cognitive development cannot be fully understood without accounting for history, community and individuals' personal histories.

\section{References}

Anderson, J. R. (1982). Acquisition of cognitive skill. Psychological review, 89 (4), 369-406.

Belenky, M. F., Clinchy, B. M., Goldberger, N. R., \& Tarule, J. M. (1986). Women's way of knowing. New York: Basic Books.

Best, J. B. (1992). Cognitive psychology (3rd edition) New York: West Publishing Co.

Brown, J.S., Collins, A., \& Duguid P. (1989). Situated cognition and the culture of learning. Educational researcher, 18 (1), 32-34.

Chi, M. T. H., Glaser, R., \& Farr, M. J. (1988). The nature of expertise. Hillsdale, NJ:Erlbaum.

Dweck, C. S., \& Elliott, E. S. (1983). Achievement motivation. In E.M. Hetherington (ed) Handbook of child psychology (4) 643-691.

Engestrom, Y. (1993). Development studies of work as a testbench of activity theory: The case of primary care medical practice. In S. Chaiklin \& J. Lave (eds). Understanding 
practice: perspectives on activity and context. Cambridge, U.K: Cambridge University Press. $64-103$.

Evans, G. (1991). Lesson cognitive demands and student processing in upper secondary mathematics. In Evans, G. (ed). Learning \& teaching cognitive skills, ACER: Melbourne, Australia.

Garner, R. (1990). When children and adults do not use learning strategies: Towards a theory of settings. Review of educational research, 60 (4), 517-529.

Gauvain, M. (1993). The development of spatial thinking in Everyday Activity. Development review, 13 (1) 92-121.

Glaser, R. (1984). Education and thinking - the role of knowledge. American psychologist, 39 (2) 93-104.

Glaser, R. (1989). Expertise and learning: How do we think about instructional processes that we have discovered knowledge structures? In D. Klahr \& K. Kotovsky (Ed) Complex Information Processing: The impact of Herbert A. Simon. Hillsdale, N.J: Erlbaum \& Associates.

Glaser. R. (1990). Reemergence of learning theory within instructional research. American psychologist, 45 (1) 29-39.

Gott, S. (1989). Apprenticeship instruction for real-world tasks: The co-ordination of procedures, mental models and strategies. In Rothhopf, E. Z. (ed) Review of research in education, Washington, DC: American Educational Research Association.

Greeno, J.G. (1989) Situations, mental models, and generative knowledge. In D.Klahr \& K. Kotovsky (ed) Complex information processing: The impact of Herbert A. Simon. Hillsdale, New Jersey: Erlbaum Associates.

Greeno, J. G., \& Simon, H. A. (1988). Problem-solving and reasoning. In R. C. Aitkinson, R. J. Hormiston, G. Findeyez and R. D. Yulle (eds) Stevens' handbook of experimental psychology and education, Vol 2. New York: Wiley.

Groen, G. J. \& Patel, P. (1988). The relationship between comprehension and reasoning in medical expertise. In Chi, M.T.H. Glaser, R \& Farr (eds). The nature of expertise. New York Erlbaum.

Lave, J. \& Wenger, E. (1991). Situated learning - legitimate peripheral participation. Cambridge: Cambridge University Press.

Leonteyev, A. N. (1981). Problems of the development of the mind. Moscow: Progress Publishers.

Luria, A. R. (1976). Cognitive development: Its cultural and social foundations. Cambridge: 
Harvard University Press.

Martin, J. R. (1970). On the reduction of "knowing that" to "knowing how". In S. M. Cahn (ed), The philosophical foundations of education (pp. 399-409). New York: Harper \& Row.

Martin, L. M. W. \& Scribner, S. (1991) Laboratory for cognitive studies of work: A case study of the intellectual implications of a new technology. Teachers College Record, 92 (4)

Newell, A. \& Simon, H. A. (1972). Human problem solving. Englewood Cliffs, N.J.: Prentice Hall.

Newman, D., Griffin, P. \& Cole, M. (1989). The construction zone: Working for cognitive change in schools. Cambridge: Cambridge University Press.

Novak, J. D. (1990). Concept maps and Vee diagrams: Two metacognitive tools to facilitate meaningful learning. Instructional science, 19 29-52.

Perkins, D., Jay, E., \& Tishman, S. (1993). Beyond abilities: A dispositional theory of thinking. Merrill-Palmer Quarterly, 39 (1), 1-21.

Prawat, R. S (1989). Promoting access to knowledge, strategy and dispositions in students: A research synthesis. Review of educational research, 59 (1) 1-41, Spring

Rogoff, B. (1990). Apprenticeship in thinking - cognitive development in social context. New York: Oxford University Press.

Rogoff, B. (1995). Observing sociocultural activity on three planes: Participatory appropriation, guided participation and apprenticeship. In J.W. Wertsch, A. Alvarez, P.del Rio, \& (eds) Sociocultural studies of mind pp 139-164. Cambridge, Mass: Cambridge University Press.

Ryle, G. (1949). The concept of mind. London: Hutchinson University Library.

Scandura, J. M. (1980). Theoretical foundations of instruction: A systems alternative to cognitive psychology. Journal of structural learning, 6, 347-394.

Scandura, J. M. (1982). Structural (cognitive tasks) analysis: a method for analysing content. Part 1: background and empirical research. Journal of structural learning, 8 101-114.

Scribner, S. (1984). Studying working intelligence. In B. Rogoff \& J. Lave (eds) Everyday Cognition: Its development in social context. Cambridge, Mass: Harvard University Press.

Scribner, S. (1985a). Knowledge at work. Anthropology and education quarterly, 16, 199-206.

Scribner, S. (1985b) Vygostky's use of history. in J.V. Wertsch (Ed).Culture, communication and cognition: Vygotskian perspectives. Cambridge: Cambridge University Press .119-145 
Scribner, S. (1992) Mind in action: A functional approach to thinking. The quarterly newsletter of the laboratory of comparative human cognition 14, (4) 103-110 (reprint of 1983 lecture).

Scribner, S., \& Beach, K. (1993). An activity theory approach to memory. Applied cognitive psychology, 7, 185-190.

Stevenson, J. C. (1986a). Adaptability: theoretical considerations. Journal of structured learning,9 107-117.

Stevenson, J. C. (1991). Cognitive structures for the teaching of adaptability in vocational education. In G. Evans (ed) Learning and teaching cognitive skills. Victoria, Australia: ACER.

Stevenson, J. C. (1994). Vocational expertise. In J. Stevenson (ed) Cognition at work: The development of vocational expertise. Adelaide, South Australia: National Centre for Vocational Education Research. 7-35.

Stevenson, J. C, McKavanagh, C. \& Evans, G. (1994). Measuring the press for skill development. In J. Stevenson (ed) Cognition at work: The development of vocational expertise. Adelaide, South Australia: National Centre for Vocational Education Research. 198 - 216.

von Glasersfeld, E. (1987). Learning as a constructive activity. In Claude Janvier (ed) Problems of representation in the teaching and learning of mathematics. Hillsdale, NJ: Lawrence Erlbaum

Voss, J. F., Blais, J., Means, M. L., Greene, T. R. \& Ahwesh, E. (1986). Informal reasoning and subject matter knowledge in the solving of economics problems by naive and novice individuals. Cognition and instruction, 3 (4) 269-302.

Vygotsky, L. S. (1978). Mind in society - the development of higher psychological processes. Harvard University Press.

Vygotsky, L. S. (1987). Thought and language. (ed A. Kouzulin). Massachussets:The MIT Press. 
Table 1

Sources of knowledge

\begin{tabular}{l|l} 
Source & Justification from theory \\
\hline History & $\begin{array}{l}\text { Knowledge based upon socio-historical development (Scribner, 1985b; } \\
\text { Vygotsky 1978) (phylogenetic development) - "legacy for individuals in } \\
\text { terms of technology, such as literacy, numbers systems, value systems, } \\
\text { scripts and norms (Rogoff, 1990:32) }\end{array}$ \\
\hline Community & $\begin{array}{l}\text { Community of practice (activity system [Vygotsky, 1978; Leonteyev, } \\
\text { 1981; Engestrom,1993) - a version of the socio-culturally-derived } \\
\text { concept of practice }\end{array}$ \\
\hline persondividuals' histories & $\begin{array}{l}\text { Individual construction - shaped by individuals' history (microgenetic } \\
\text { development ("moment to moment learning by individuals .. built on } \\
\text { individual genetic and socio-cultural background", [Rogoff, 1990:32]) } \\
\text { contributing to ontogenetic development "life history of the individual" } \\
\text { (Scribner, 1985b); or "the change in thinking and behaving arising in the } \\
\text { history of individuals" (Rogoff, 1990:32) }\end{array}$
\end{tabular}

